\title{
Ethinyl Estradiol/Norgestrel
}

National Cancer Institute

\section{Source}

National Cancer Institute. Ethinyl Estradiol/Norgestrel. NCI Thesaurus. Code C12162.

A combination of two steroid sex hormones, the semisynthetic estrogen ethinyl estradiol and the synthetic progestogen norgestrel, with contraceptive activity. The combination of ethinyl estradiol with norgestrel suppresses the hypothalamic-pituitary system, leading to an inhibition of the release of follicle stimulating hormone (FSH), thus suppressing the development of ovarian follicles. The release of luteinizing hormone (LH) is also inhibited, thus preventing ovulation. In addition, thickening of the cervical mucus and the endometrium is promoted, thereby altering the endometrium in such a way as to discourage implantation. 